\title{
ACTIVE LEARNING AND CRITICAL THINKING IN FASHION DESIGN EDUCATION
}

\author{
Mette Nørgaard TERKILDSEN and Malene PILGAARD HARSAAE \\ VIA University College, Denmark
}

\begin{abstract}
Design for sustainability is not a new concept, it has, however, evolved from a single product to a complex system, which places design and engineering in the tension between consumption dynamics, product thinking and system thinking, accompanied by an increased need to understand user values to qualify, operate and integrate "sustainable product strategies." Throughout history, fashion educations have subjected to support the interest of the fashion industry and its changing conditions. However, the present structure (Fast fashion) has resulted in a reduced focus on people and products. Consequently, we find that "supporting the interest of the industry" might not be uncritically to follow the current path of training students based on the market indication and mindset of the fast-fashion paradigm. Instead, we advocate that education has an obligation to train students to address and rethink fashion strategies and product development in the transition towards sustainability and social responsibility; therefore, we see education as an accelerator for change. This article presents a didactic approach to foster students' ability to diverge between zooming out and zooming in as it enables exploratory, action-orientated, and transformative learning and encourages students to think critically and systematically. Zooming out relates to the context or the bigger picture. Through empirical research, students experience and establish what is going on as opposed to speculating on what might be going on.
\end{abstract}

Keywords: Responsible, available, durability, viability, desirability

\section{INTRODUCTION}

There is a burgeoning acknowledgement that the fashion system needs new approaches and alternative business models to improve its currently devastating impact on the environment [1], [2]. Industry change initiatives are dominated by a focus on alternative materials such as organic cotton and recycled polyester. Changes that primarily seek to maintain the current 'fast fashion' approach with a focus on quantity and price, but with the consumption of materials with less environmental impact. An approach, which maintains the mechanisms of uncritically producing quantities of clothing products for the mass market with the approach of 'one size fits all.' Archetypically, fast-fashion products are designed inside out, as needs are interpreted and put together based on trend and requirements specified by sales and marketing functions. In fast fashion, designers commonly do not interact directly with potential customers, but draft designs base on-trend interpretation and price segmentation. In this discourse, understanding of the users' environment, points of view, and everyday practice are downgraded. Breaking free from fast fashion, this article advocates that rethinking apparel strategies requires understanding customers' reality and values, thus allow realism and pragmatism to be equated speed and price to market. From 2016 - 2019, two individual PhD projects [3], [4] have collaboratively collected data about Danish women's relationship and interaction with clothes and fashion. The shared findings from the two projects provide an empirical foundation that indicated a need for the industry to view product development and customer expectation more nuanced than what can be contained in the present fast fashion structure. These insights provided the foundation for a summer school course "Fashion Strategies. Seeing, Knowing, and Rethinking." This course constitutes the case and didactic approach of zooming in and zooming out [5], and active learning [5] presented in this article. Zooming in on" and "zooming out of" practice, in a real-time context, relates to the process of shifting perspectives, to understand and grasp the nuances and extent of a given challenge. The course requires, student to actively research, interact and map patterns of needs and behaviour, to get a sense of what would make a significant difference, as well as define for whom and why- thus building knowledge by discovering patterns and its relations to the practice of buying, consuming and wearing apparel. 


\subsection{The concept of niche}

Both studies identified cause for actions as well as multiple niches within clothing consumption to be addressed. Qualifying product offerings by understanding customer needs and preferences is foregrounded in both studies. We advocate that education links concepts and product offerings in a realworld context, thus promotes a depth of understanding as well as adaptability of knowledge needed to create sustainable product strategies and inclusive product development structures. Mass-produced clothes not only put pressure on the environment; it is also put pressure on both retail and customers. Acknowledging that fast fashion has made it affordable for everyone to buy fashionable products, not everyone has the pleasure of access to style, as real people come in a variety of shapes and sizes, which often deviate from industry standards and assumptions of average. We argue that a system can be too simple and single-sided; our research and teaching suggest revisiting the market (here in a Danish context) to assess the cause and consequences of the present structure, thus determine the unmet need of the customer. Unmet needs are considered strategically important, as they represent opportunities for businesses [6] and point at ways to break into market share or increase existing share in the market. Overall thematic analyses of the primary data emphasized balancing responsibility, durability, viability, desirability. One of the challenges stressed by the fast fashion paradigm relates to short timeframes and unclear expectations, caused by competition mainly based on price and speed to market instead of values and to qualify the product or services brought to the market. In this view, a niche market is not segmentation, as segmentation is the process of breaking the mass market into smaller pieces (topdown). In contrast, we argue that a niche market starts from specialization and variation and builds up.

\subsection{Product design}

Product design can be viewed as a single- dominant design discourse or as an inclusive and multiple oriented matter viewed in a holistic and transdisciplinary discourse. The first relates to one dominant value and practice that builds on ideal norms and linear development processes, thus creating a dichotomy of either you 'Fit in' or you do not. In contrast, multiple orientated discourse is a product of multiple values and processes that view user, product, and the context in a bigger picture, exploring ways of understanding diversity, multiple perspectives, and practices. By adopting a transdisciplinary approach, we move instruction beyond merely blending disciplines. Rather we link concepts and skills in a real-world context and promote depth of understanding as well as adaptability of knowledge needed to create inclusive design and engineering in apparel. The fashion industry reaches an increasingly diverse target audience, and consequently, product variation and product inclusion are a way of understanding diversity. Technological advancement in product development is paving the way for the apparel industry.

\section{EXPLORING REALITY - A DIDACTIC APPROACH}

The course "Fashion strategies, seeing, knowing and rethinking" provided the student with an overview of topics and issues central to Strategic Design and product development processes, with an emphasis on the relationships between design, experience, body, society, and buying behaviour. An intensive three-week course provided the student insight multidisciplinary perspectives that contribute to creating a product strategy in fashion apparel. Based on Critical readings and discussions, case studies, guest lectures, and practice-based fieldwork, the course address strategic key elements prior to production where trend, design, technology, and customer preferences (physical and social) synthesize to inform a given product strategy. Utilizing knowledge building through empirical research, workshops, reflection, and decision-making activities, the students researched and mapped potential fashion strategies. The core of the courses was to engage students with real reality to explore mechanisms and structures within the field of fashion. Through their empirical research, the students explore reality-through empirical research, e.g., observations, conversations, and engaging in the environment. Thereby they experience and establish what is going on as opposed to speculating on what might be going on. The courses were planned as an interaction between deductive and inductive methods (lectures) and active (studentdriven) learning with concurrent guidance, small presentations, and feedback. Figure 1 illustrates the overall structure and didactic approach of the course. 


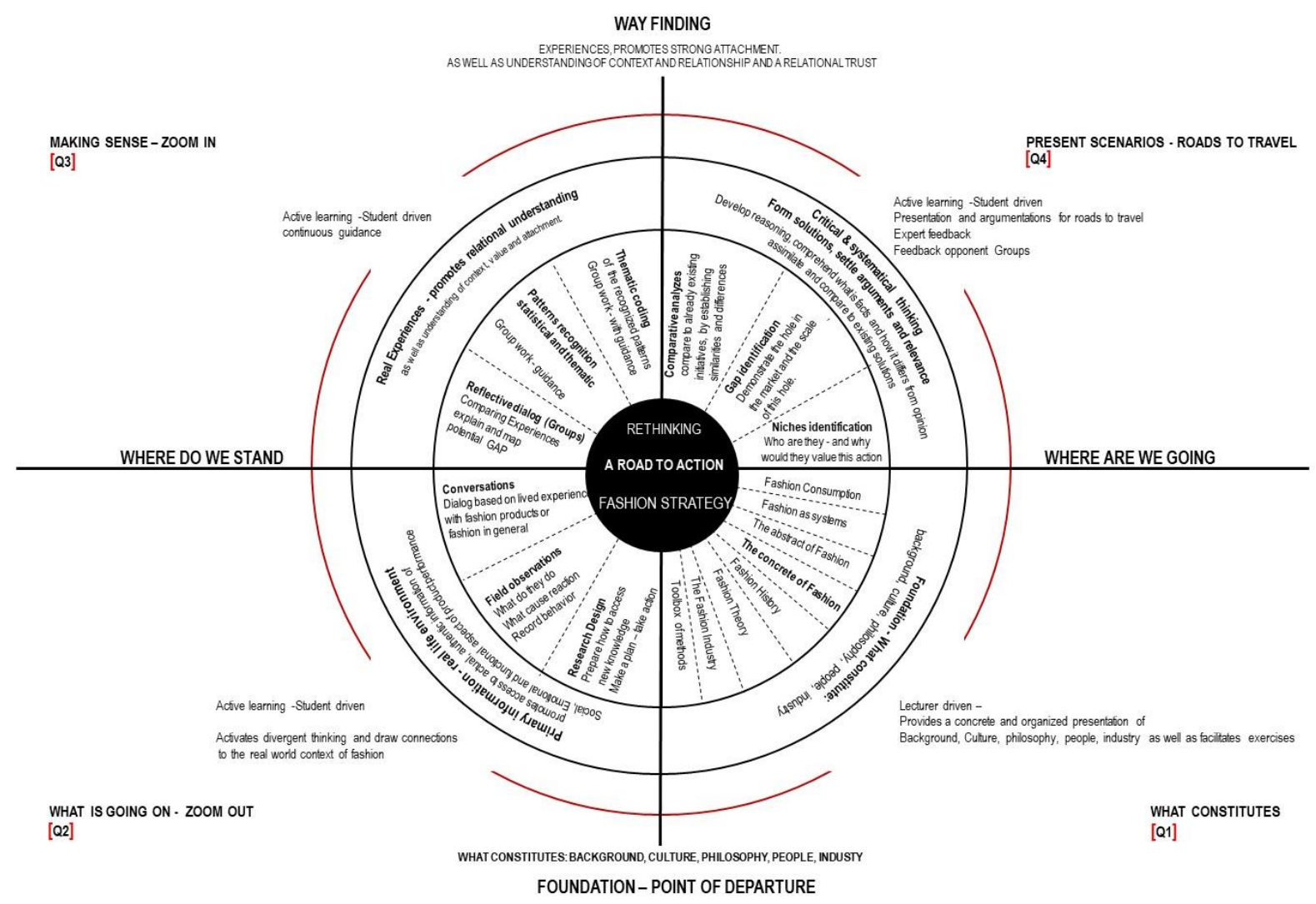

Figure 1. Didactic approach

The four quadrants constituting the circle illustrate the didactic approach applied to the course. In this situation, the teachers could, in their experience of practice (the fashion industry), alternate between the different roles: lecturer [Q1], facilitator [Q2], guidance [Q3], and expert [Q4]. Alternatively, stakeholders from the industry can participate and manage the role of the expert.

To provide foundation, context, as well as facilitate discussions, the first quadrant [Q1] "What constitutes," introduce to the Fashion System, the methodology and the disciplines involved in creating a product strategy and discover how to create alternative strategies. This includes an introduction to fashion as a term, fashion as history and theory, fashion design as a term, products as fashion objects, with the body as a given. Furthermore, this part elaborates on the fashion industry and its impact, environmental, emotional, and practical, and the technologies and business models related to hereto. Throughout the sessions, the students engage in exercise and discussions of how we see and perceive fashion and the mechanisms diffusing fashion. The results/knowledge guide students to create a framework or understanding of the terms Fashion market, fashion design, and product development. [Q2] The reason for the students to be actively involved in the learning process, relates to the process of having the students engage in and experience the topic first-hand. This allows the students to reflect upon ideas in a context, thus qualify ideas in a real-world setting. Keeping students mentally, physically, and emotionally active in their knowledge building, stimulates their ability to reflect and qualify the cause and impact of a given situation. The data collection focusses on the what, the who, and the why. The students observe context, thus accessed, who is affected, and why they were affected, the scale of the situation, the need, and the cause and consequences of the needs. [Q3] The students describe the relational elements established in the collected data. Through reflective dialog- they make sense of the collected data (secondary and primary), here, group members are sharing and discussing the information embedded in the data. Followed by a thematic coding of the information. (Discover patterns) [Q4] Critical \& systematic thinking and transformative perspective. Perspective transformation may lead to new roads to travel. In this context, transformative perspectives are to be understood as understanding multiple perspectives of the phenomenon in question leading to an intentional action based on insights. Here, market evidence is an expansion of consciousness and worldviews in that it is based on a reality positioned in a concrete context. The students comprehend what the fact (real life) is and how it is 
different from opinion and what is out there. They develop reasoning based on market evidence, product evidence, and human values - Where, What and Whom - Why, and assimilate ideas to a specific context (niche). Designing a strategy means having a plan of action designed to achieve a long-term or overall aim. In this phase, the student has built knowledge through information gained from lectures and secondary research, as well as experiences gained through primary research (field research zoom out,), reflective dialog- thematic coding as well as statistical evidence and is now in the position of pointing at possible roads to travel. To qualify the solutions, the students pitch to experts as well as to the other groups. The feedback is reviewed and used to qualify the proposed roads to travel. The students are now required to loop - based on the thematic codes and feedback from the pitch student, repeat the field research. However, now they Zoom in to establish if the identified codes may be confirmed, this realization poses way for the students to determine which insights put into action could support and inform a Fashion strategy as illustrated in figure 2.

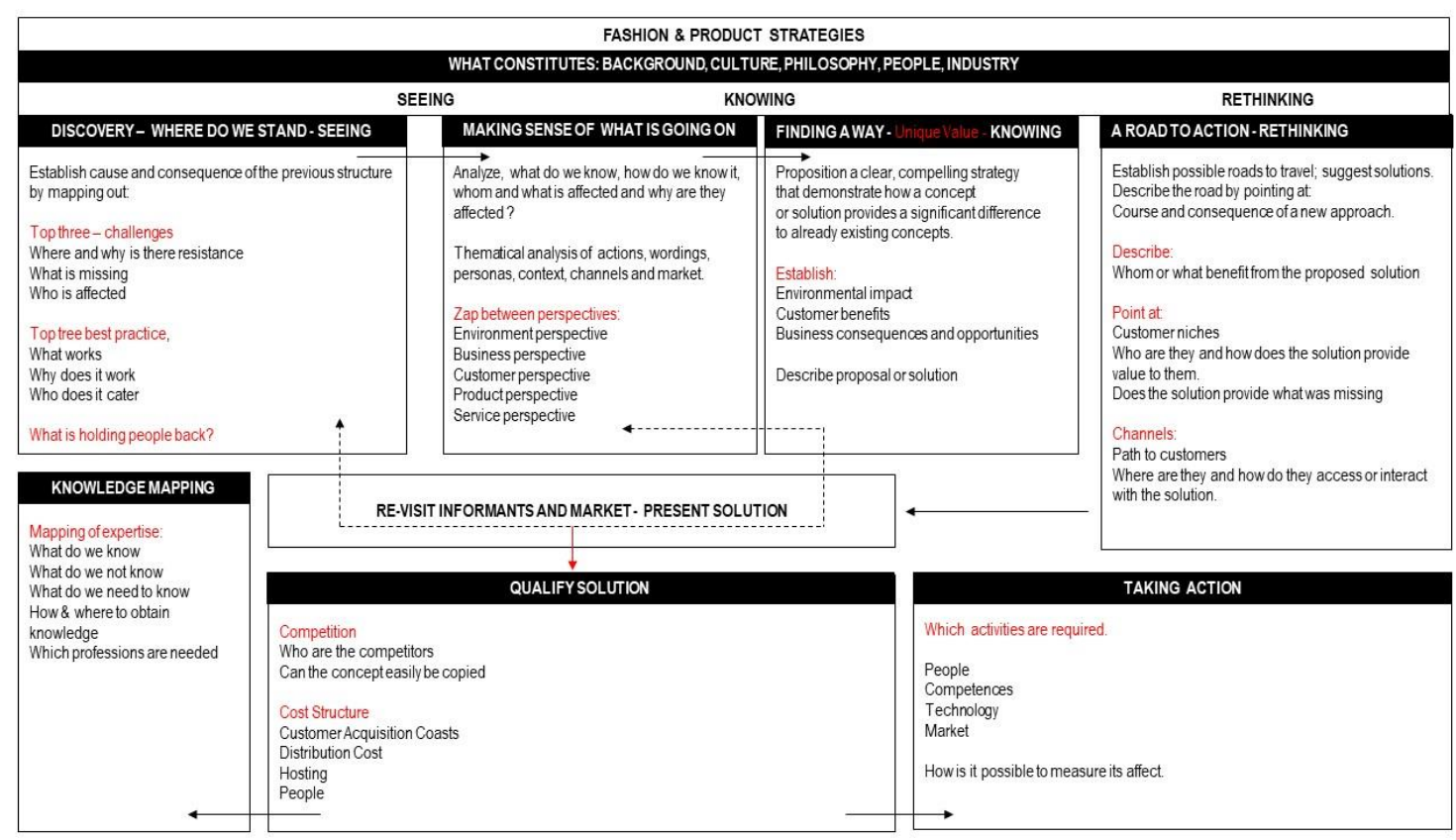

Figure 2. Model of Seeing, Knowing, and Rethinking

The didactic approach is designed to foster students' ability to diverge between zooming out and zooming in as it enables exploratory, action-orientated, and transformative learning. It encourages students to think critically and systematically. The process of zooming out relates to the context or the bigger picture. In this face, students discover patterns and map the territory, thus establish establishing causes and effects before acting. Based on discovered patterns and mapped territory, they zoom in on details. Understanding details is like building blocks put together; they form solutions and settle arguments and relevance. The aspect of critical and systematic thinking embedded in the didactic approach relates to constantly knowledge mapping - what do we know - what don't we know - which action can be taken to acquire the necessary knowledge and what could be the consequence of the action, exemplified in table 1. Finding: Reduce the customers need to source information's was brought forward by customers as they stressed a lack of transparency and trust to be a significant obstacle: "How can I be sure of what I am buying into? It is so unclear - to be honest, I think the industry is more about telling than doing." (Danish women, age 23). In conversation with women, key parameters such as Natural fibres, timeless silhouettes, flattering, and functional fit and durability were emphasized as selling points, as it was found desirable not only form an environmental perspective but also from an egocentric style perspective. Further defining quality proved highly subjective, and the evaluation of product quality was often based on fit and sizing criteria. To promote sustainable consumption, they concluded that we need to speak to egotistical needs and promote value to consumers. Although the group was surprised and perhaps also disappointed in people's attitudes towards sustainable consumption, they were now very motivated to address communication or lack of communication. Revisiting the field, they now compared fashion with food or beauty products, and in conversations with participants, they now 
asked the same question based on food and apparel or beauty products and apparel: E.g., Do you consider how the food you are eating is produced? - and do you consider how the clothes you wear directly on your body are produced? This way of questioning (shifting perspectives) brought about a different level to the conversation as informants now reflected upon why they, for example, always check the level of chemistry in beauty products, but not in clothing. Most respondents made use of the chemistry app which, based on scanned codes, describe the content of beauty products. When asked why they made use of the app, they stress that it was easy to use and gave immediate feedback, so they did not have to source for information. As a result, this group pointed at a fashion communication strategy - to facilitate that customers could make informed decisions when buying fashion products.

Table 1. Example of knowledge mapping and how students constantly update and refine

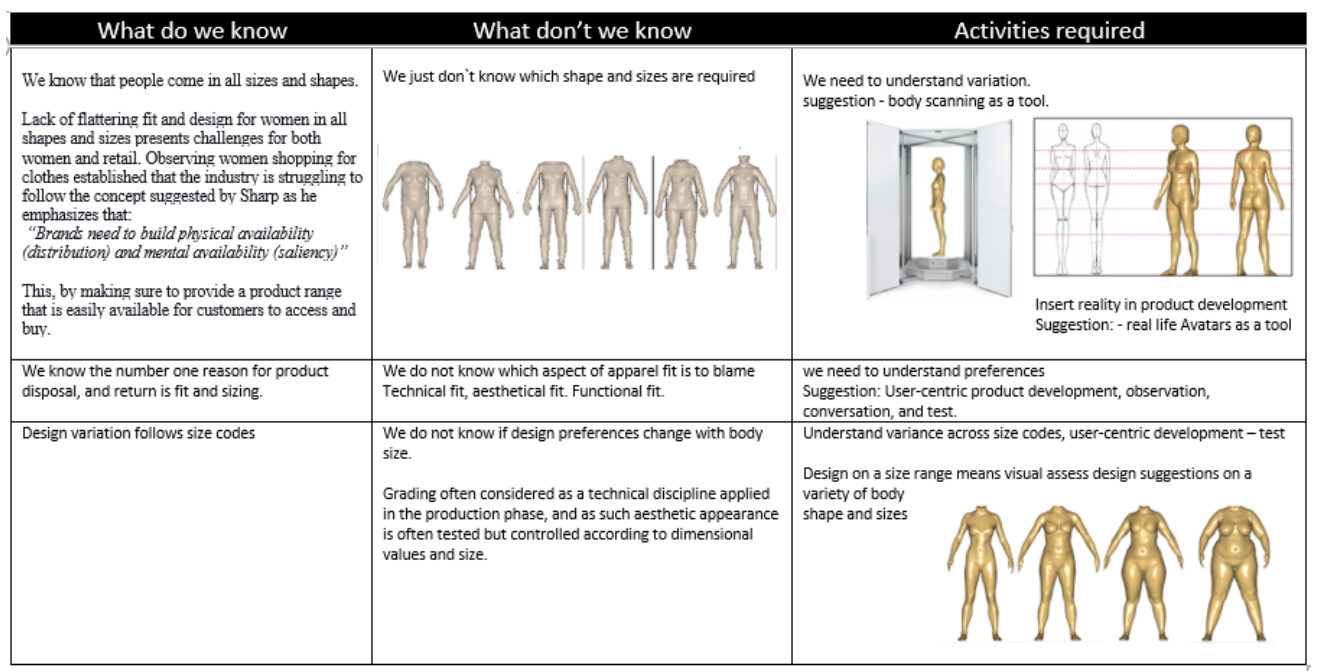

\subsection{Cause, context, and values}

The course was situated in a relational development fashion systems framework, which point of departure elates to fashion in general and more specific to the mutually influential relations between industry, individuals, product, and context, which calls for an integrated approach to building knowledge. The course demonstrated that research and interaction with user, environment, and context contributed to student engagement and taking greater ownership of the assignment (emotional and intellectual). Further, it was apparent how perspectives and suggested strategies changed throughout the course, and the level of abstraction in the discussions raised proportionally to the construction of knowledge. The requirement of a holistic and interdisciplinary approach was demonstrated as several groups made use of expert knowledge to push forward and qualify ideas. Findings clearly demonstrated that fashion-forward from a consumer perspective not necessarily comply with fast and more, as stated by a participant. "I do not want a lot of clothes; I just want the right clothes." (Danish Women Age 29). Matching people and products proved highly stressful, and despite technology advancement, customers requested transparency and improved communication, as understanding quality, fit, and design variation, not to mention size codes stressed inexact and misleading. Product performance was foregrounded both positive and negative, while a significant number of women pointed to inadequate fit as a major topic to be addressed, the topic of fit also proved significant in product attachment as flattering fit, unique cuts and silhouettes were emphasized. Anecdotal evidence of retail and industrial tendency to make social judgments based on body shapes was brought forward. Lack of flattering fit and design for women in all shapes and sizes presents challenges for both women and retail. Observing women shopping for clothes clearly established that the industry is struggling to follow the concept suggested by Sharp [7] "Brands need to build physical availability (distribution) and mental availability (saliency)" This by making sure to provide a product range that is easily available for customers to access and buy. Product availability proved highly stigmatizing as the apparel product range appears to be designed for the few with the aim of targeting the majority. From a lean perspective, it is luring to simplify processes as well as product offerings, but from the perspective of the customers, it was perceived as limiting and exclusionary. Further, it was found that product design and availability changes with size codes, as the aesthetic presented in size range 34-42 proved different than 44 and up. It was by women in the upper size segment stressed as problematic as they felt limited in pursuing a 
personal style. Consistency and recognizability are much more important than a number. Customers find it difficult to place themselves within the numerical sizing system. Further, it was clear that taking a holistic approach connects to the fashion system's environmental impact, as it is affected by its understanding of the market, its customer, and product performance (social, emotional, and functional) situated in the contexts of everyday life.

\section{DISCUSSION}

Research and interacting with customers and customer environments provided the students with a firsthand understanding of product performance in each context. When creating a fashion strategy, we emphasize the importance of paying attention to understand how a service or product fits in the life of the customers. Linking product performance and product attachment back to purchasing criteria and personal values, as it provides insights into needs and preferences (met and unmet). In doing so, we shift the perspective from production to a lifestyle perspective. Throughout the course, the students were required to zap between perspectives (Zoom in and out), this change in perspectives provided an indepth understanding of differences and similarities, that allowed the student to qualify solutions constantly. Each group established patterns of recognition to be pursued in a specific product or fashion strategy, and although significant variation in topic and target audience, all groups were able to establish determinants or influential factors deducted from customers stories of experiences, associations, meanings, and interactions with fashion products. Acknowledging technology as a significant factor and tool, allowing individualization to take part in product development, we argue that no virtual experience can surpass nor ignore the physical experience and touchpoints between customers and products. By that, we mean that the quality and relevance of any product are evaluated only by its performance in the real world. Most technological solutions are currently aimed at professionals to do their jobs more efficiently; however, for the customers to feel a significant difference, the technological advancement must be reflected in product range and availability.

\section{CONCLUDING REMARKS}

We argue that one insightful lens of discovering sustainable product strategies derive from reality itself taking an active part in understanding cause, context, and value. The combination of field research, empathy, and technology creates a strong foundation for sustainable and inclusive product design. In this understanding, field observation is not just about describing what we see; it is about identifying what is missing, and in doing so, it can be argued that it is prospective but grounded in a profound understanding of context. The understanding of the principle and how to vary its' operations, enables the student to access the knowledge of what is significant to its user, how it fits in the larger scheme of things (the surroundings and fashion in general) and thereby understanding the main determinants of the many niches constituting the real reality. Certain core principles are relevant to inform sustainable and inclusive product strategies and businesses. First and foremost, to continuously address the various needs of current and future customers. Instead of creating for one with the purpose of targeting all, strive for inclusion by acknowledging the complexity of humans and create for everyone and with everyone.

\section{REFERENCES}

[1] Ellen MacArthur Foundation, (2017) A new textiles economy: Redesigning fashion's future, http://www.ellenmacarthurfoundation.org/publications.

[2] Raworth, Kate (2017). Doughnut Economics. Cornerstone.

[3] Terkildsen, M.N. (Forthcoming 2020) To [Fit] In Danish Fashion, Towards inclusive apparel fit and sizing structures - on the foundation of body logic, Ph.D. Dissertation.

[4] Harsaae, M.P. (Forthcoming 2020) Age-ency in the Construction of Style Narratives Ph.D. Dissertation.

[5] McManus, G. and Powe, M. (2009) The Creation of Sustainable Value.

[6] Biggs, J. and Tang, C. (2011) Teaching for Quality Learning at University. Open University Press.

[7] Sharp, Bryan, (2016). How Brands Grow, Oxford University Press. 